EPJ Web of Conferences 24, 04003 (2012)

DOI: $10.1051 /$ epjconf/20122404003

(C) Owned by the authors, published by EDP Sciences - SIF, 2012

\title{
Monitoring physical properties of a submarine groundwater discharge source at Kalogria Bay, SW Peloponnissos, Greece
}

\author{
A. P. Karageorgis, V. P. Papadopoulos, D. Georgopoulos, \\ Th. D. Kanellopoulos and E. Papathanassiou
}

Hellenic Centre for Marine Research, Institute of Oceanography 46.7 km Athens-Sounio Avenue, 19013 Anavyssos, Greece

\begin{abstract}
An impressive SGD in Kalogria Bay (SW Peloponnissos) was surveyed for the first time in 2006, revealing the existence of 2 major and 2 minor point sources of freshwater (salinity $\sim 1-2$ ); the discharge was $\sim 1000 \mathrm{~m}^{3} \mathrm{~h}^{-1}$. The major point source was located in a karstic cavity at $25 \mathrm{~m}$ depth. In July 2009, and for a period of one year, the site was monitored intensively. During summer, the underwater discharge was not very strong, the water was flowing from many dispersed points, and salinity range was 20-36. During autumn and winter, flow velocity increased considerably $\left(>1 \mathrm{~ms}^{-1}\right)$, and the SGDs discharged water of low salinity $(<2)$. Gradually, the smaller SGDs ceased their operation, and the major SGD emanated brackish water during spring and summer, thus hampering the possibilities of freshwater exploitation, in a touristic area which suffers from great aridity and water demand is high during summer.
\end{abstract}

\section{Introduction}

Knowledge concerning submarine groundwater discharges (SGDs) has existed for many centuries [1]. However, SGDs were neglected scientifically

This is an Open Access article distributed under the terms of the Creative Commons Attribution License 2.0, which permits unrestricted use, distribution, and reproduction in any medium, provided the original work is properly cited. 


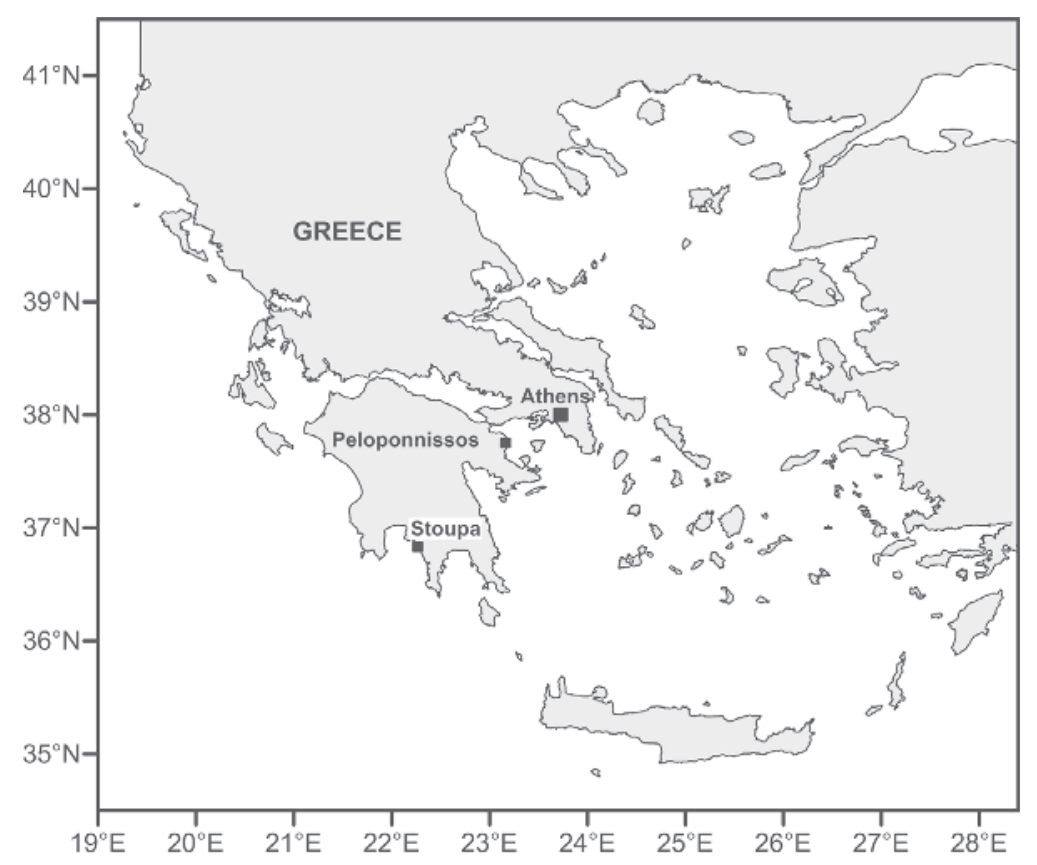

Figure 1: Study area location map.

for many years because of the difficulty in assessment and the perception that the process was unimportant [2]. Within the last two decades, that notion has changed, and now there is growing agreement that groundwater inputs can be chemically and ecological important to coastal waters [2]. Here we present new data regarding a large karstic freshwater SGD situated in Kalogria Bay, near Stoupa town, in SW Peloponnissos, Greece (fig. 1). The site was first visited in November and December 2006. During the latter visit, a multifaceted operation with divers, a remote operated vehicle, a portable CTD, and other equipment was implemented, which provided ample samples, videos, and evidence that the SGD was emanating freshwater (salinity $<1$ ). This particular area of Greece (Mani) is well-known for its dry climate, and very low rainfall. In Stoupa, drinking water coming from municipal drill holes has low quality. In that sense, a study of the SGD appeared as a possibility to using the water for drinking purposes, especially during summer, when tourism increases water demand substantially. 


\section{Methods}

The study site was difficult to survey using traditional techniques (e.g. CTD profiles, and water sample collection with Niskin bottles), because of the high current created at the surface from the upwelling freshwater which did not permit the boat to stand over the SGD, even when two heavy anchors were used. All bottle samples were collected by divers at $25 \mathrm{~m}, 20 \mathrm{~m}, 10 \mathrm{~m}$, and at the surface.

In order to collect time-series data, a lander was designed and modified often, according to changes of the underwater morphology. Two conductivity/temperature sensors Seabird SBE-37 and two specially designed flowmeters (Sensordata 6000) were deployed most of the time to collect data every $30 \mathrm{~min}$. The gamma-ray spectrometer KATERINA was deployed to measure radionuclides spectra [3]. The data were collected over a period of one year; July 2009-July 2010. During this period, the study area was visited 9 times. In the period 14/11/2009 to $20 / 1 / 2010$ the lander was deployed near the major SGD, but not exactly inside the core, due to strong underwater currents, which could be dangerous for the divers (abrupt ascend). Detailed bathymetry (ELAC SEABEAM 1185) and geophysical measurements (BOOMER, Geoacoustics Ltd.) were conducted in November 2009, and DGPS was used for accurate positioning of the research/diving boat 'Orion'.

\section{Results and discussion}

The groundwater emanates from a karstic limestone formation at $\sim 25 \mathrm{~m}$ depth. The detailed bathymetric map, together with visual observations revealed that the SGDs' system is formed in the vicinity of two crossing faults, with almost vertical walls (fig. 2). According to the season, up to 4 SGDs of lower magnitude appeared in the broader seabed depression, which has overall dimensions of $\sim 50 \times 25 \mathrm{~m}$ (fig. 3). The immense flow of the main SGD is visible at the sea surface throughout the year as a gyre with a diameter varying from 20 to $60 \mathrm{~m}$, proportional to the underwater discharge.

This morphology was maintained unaltered between 11-2006 and 2-2008. In July 2009, the underwater morphology appeared completely changed, as the roof of a cave, near the major SGD, collapsed almost entirely. The second SGD was completely filled with sand, and the two smaller ones became inactive. A possible explanation for the collapse of the cave roof could be related to the extremely high rainfall that occurred during the winter and 


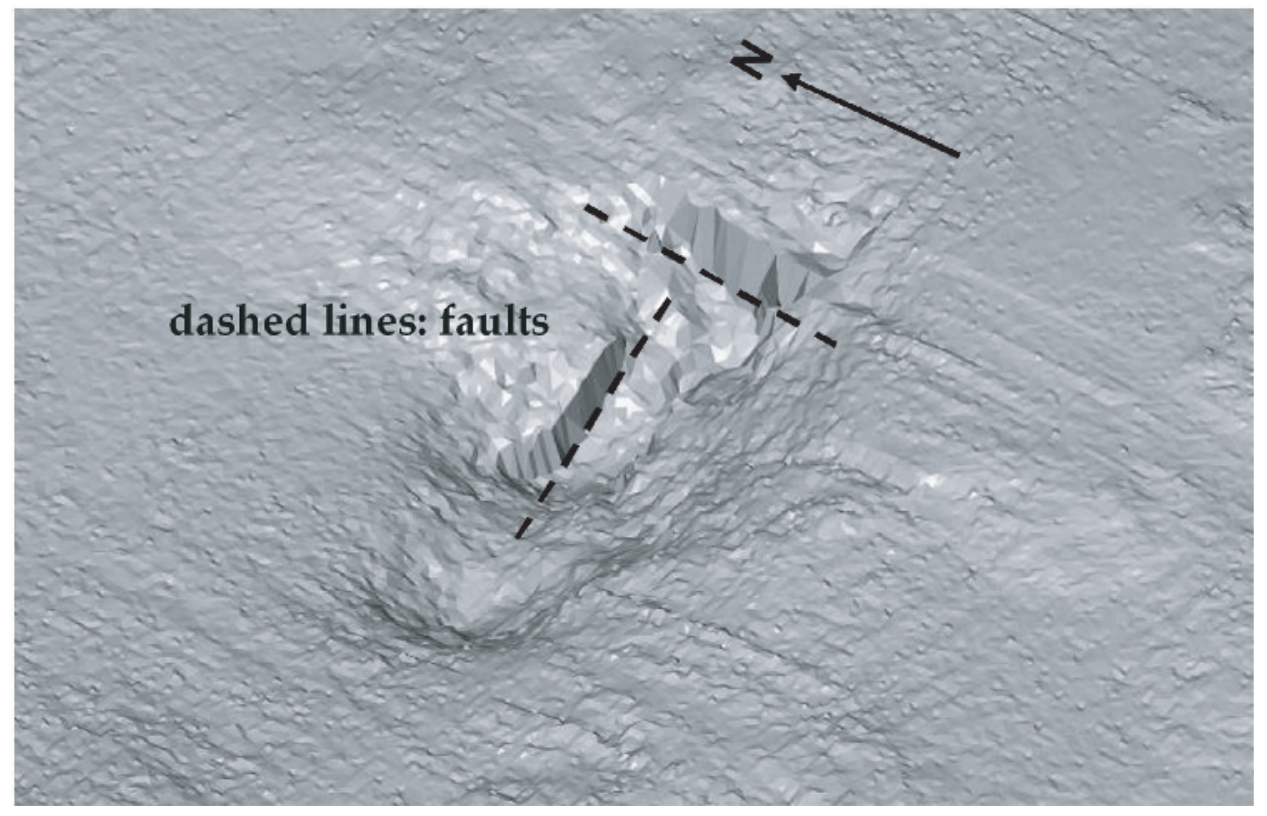

Figure 2: Three-dimensional view of the seabed depression, where the SGDs appear. The major SGD is located in the area where the two fault lines cross.

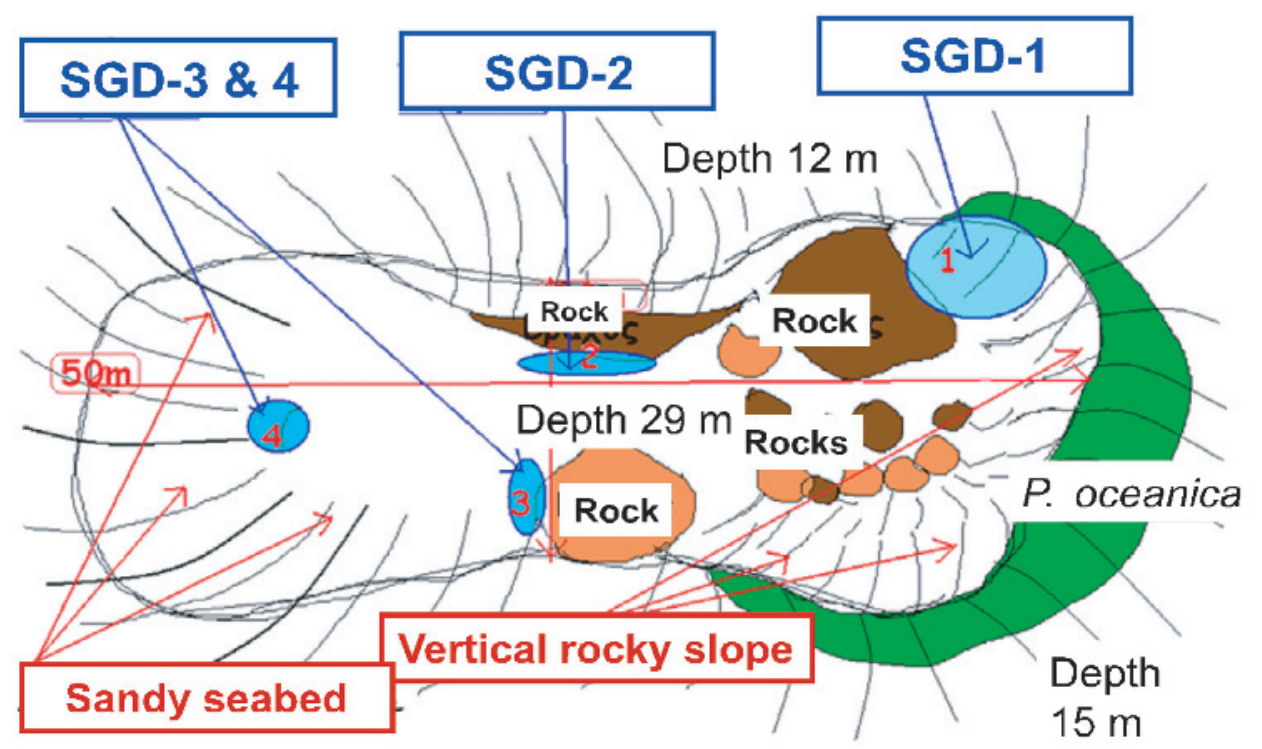

Figure 3: Sketch of the Kalogria Bay submarine groundwater springs, and the surrounding area. 
spring of 2009. Residents of Kalogria stated that during March 2009, after an intense rainfall, the SGD was 'boiling' at the sea surface, other smaller SGDs in the bay were also very active, and the sea was colored red. The red color is attributed to 'terra rossa', which is the final product of limestone dissolution during karst formation, and was transported to the sea during the intense flushing event.

During July 2009, when monitoring commenced, salinity measured in various spots was high (20-36). This behavior continued throughout August and September 2009 (fig. 4a). However, it should not be disregarded that all measurements conducted in from July 2009 to mid October 2009 reflect summer and early autumn conditions, where rainfalls are practically absent in this territory, and therefore freshwater inputs from the land should be at the lowest levels. In this perspective, the entire SGD represents minimum freshwater outflow, thus allowing faster mixing with the sea water and brackish character of the outflowing water. Measured flow velocity was on average $0.25 \mathrm{~m} \mathrm{~s}^{-1}$ (fig. $4 \mathrm{~b}$ ), which corresponds to $900 \mathrm{~m}^{3} \mathrm{~h}^{-1}$, if we assume that all small discharges cover a surface of just one $\mathrm{m}^{2}$. This is a very conservative assumption, and the discharge may be many times higher.

Low salinity water discharge $(<2)$ prevailed in mid-October (fig. 4a) accompanied by high flow velocities $\left(>1.2 \mathrm{~m} \mathrm{~s}^{-1}\right.$; fig. $\left.4 \mathrm{~b}\right)$. On the $13^{\text {th }}$ of November the lander was recovered with great difficulty due to high turbulence and very poor visibility, and on the $14^{\text {th }}$ of November it was deployed nearby the main SGD, which was inaccessible from the divers. Until the following recovery and re-deployment (20 January 2010) salinity varied substantially, from low values $(<5)$ to very high values $\sim 37$ (fig. $4 \mathrm{a}$ ). Flow velocity varied in the opposite manner, i.e. lower velocities corresponded to high salinities and high flow velocities $\left(>1 \mathrm{~m} \mathrm{~s}^{-1}\right)$ were directly related to low salinities (figs. 4a, b). Such irregular behavior was observed until March 2010, when low salinities and high flow velocities prevailed again. In May 2010, salinity increased abruptly from 4 to 13 within a few hours, whereas flow velocity decreased slightly. This sudden change can be attributed to salinization of the aquifer, possibly related to a general decrease of freshwater volume in the karst system, together with increased water demand for irrigation. The SGD continued discharging brackish water until the end of the observation period, in the beginning of July 2010, despite some decrease in salinity during June (fig. 4a).

One year of continuous observations of salinity and flow velocity at the point source SGD of Kalogria Bay showed in general great seasonal variability. It appears that high discharge is most often resulting to low salinity, but extreme gaps between recovery and re-deployment of the sensors within 


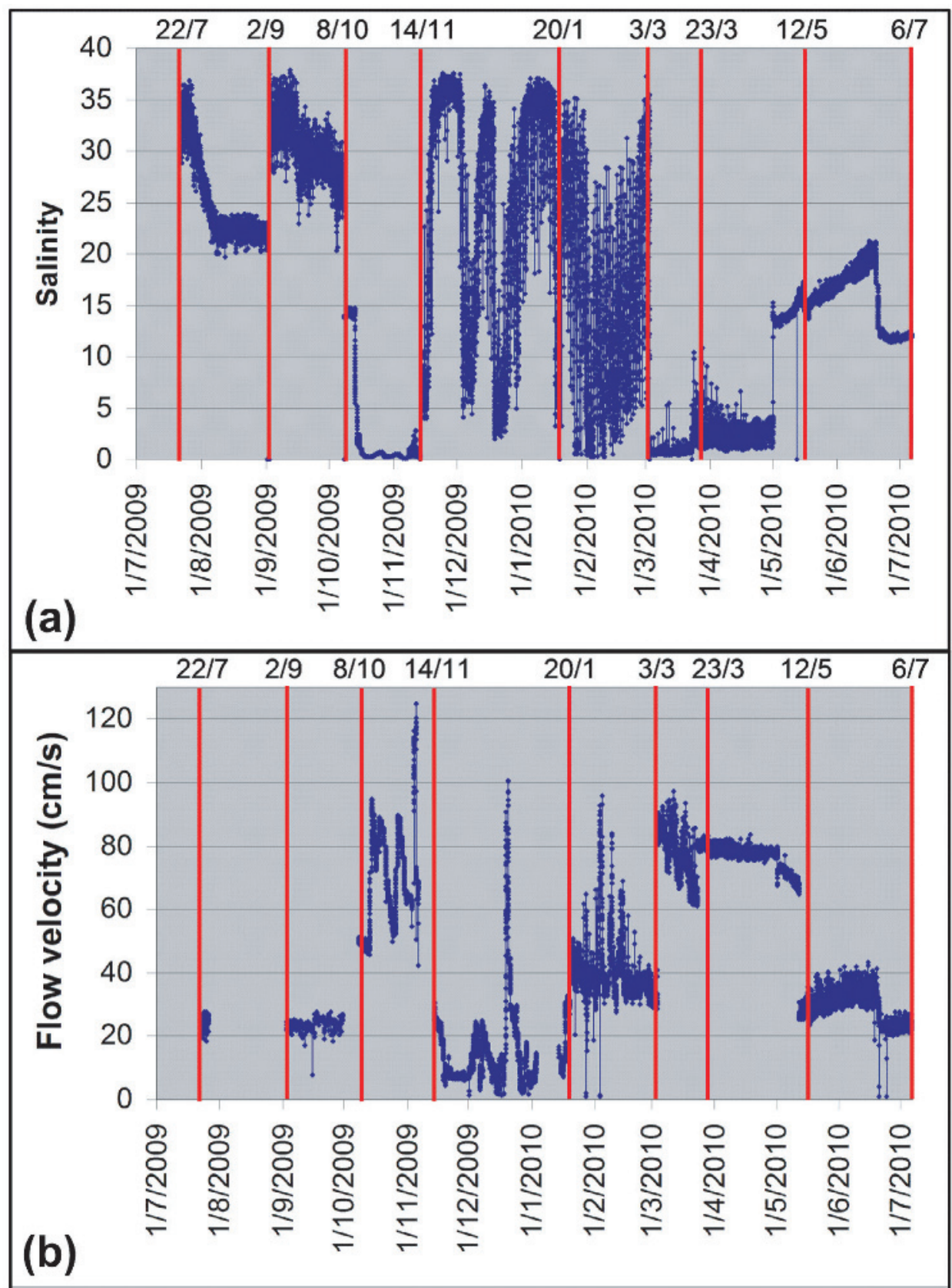

Figure 4: (a) Salinity time-series and (b) flow velocity time-series. Red lines indicate deployment dates. 
$24 \mathrm{~h}$ suggest that the system is influenced by high turbulence. Positioning of the instruments at slightly different locations often resulted in unexpected differences both in salinity and flow velocity. One of the reasons that could explain such variability is probably the inability to position the lander with the sensors exactly on top of the major SGD, since the latter was covered by a big $(5 \times 4 \times 1 \mathrm{~m})$ limestone rock, thus enhancing rapid mixing of freshwater with marine water. However, during high discharge periods, the sensors recorded clearly freshwater emanating under and around the rock. An attempt to correlate rainfall with high discharge largely failed because gauging stations were several kilometers away from the study area.

An additional problem caused by the presence of the limestone rock has to do with the estimation of the exact geometry of the point source SGD. In the absence of accurate knowledge of the active discharge area, the actual discharge cannot be measured accurately. Our estimates are based on a simple assumption that freshwater flows from approximately a total area of just one square meter.

\section{Conclusions}

The Kalogria SGD is a unique site that currently concentrates a wealth of information, far more than any other Greek SGDs. The initial target of the study was to ascertain that potable water could be available for the local community. Our survey proved that the SGD is largely unsuitable for exploitation. During the autumn and winter freshwater emanates from the spring, however strong turbulence causes fast mixing with marine water of high salinity. At the same time the flow velocity is generally high, and water discharge was more than $3600 \mathrm{~m}^{3} \mathrm{~h}^{-1}$. On the contrary, during spring and summer the spring's water was brackish, and accompanied by relatively low discharge $\left(\sim 750 \mathrm{~m}^{3} \mathrm{~h}^{-1}\right)$.

The high variability of salinity, flow velocity (and temperature; not shown here) measurements show clearly that the SGD is a highly dynamic environment. The presence of a limestone rock, which covers the primary SGD, makes it difficult to estimate the active area of the seabed where freshwater emanates, thus the water discharge figures are calculated assuming that the active surface is $1 \mathrm{~m}^{2}$.

Additional work in needed to identify the exact mechanism that enhances rapid mixing, and possibly the hydraulic conditions, which favor the salinization of the aquifer during spring and summer. 


\section{References}

[1] UNESCO, Submarine groundwater discharge. Management implications, measurements and effects. IHP-VI, Series on Groundwater No. 5, IOC Manuals and Guides No. 44 (United Nations, Paris) 2004.

[2] BuRnetT W. C., BOKUniewiCZ H., HUETTEL M., MOORE W. S., TANIGUCHI M., Biogeochemistry 66 (2003) 3-33.

[3] TSABARIS C., SCHOLTEN J., KARAGEORGIS A. P., COMMANDUCCI J.-F., GEORGOPOULOS D., KWONG L.-L. W., PAPATHAnAssiou E., Radiat. Prot. Dosim. (2010) 1-9. DOI:10.1093/ rpd/ncq190. 